\title{
Extreme insulin resistance during pregnancy: a therapeutic challenge
}

\author{
Ulla Kampmann'1, Per Glud Ovesen², Niels Møller ${ }^{3}$ and Jens Fuglsang ${ }^{2}$ \\ 1Steno Diabetes Center Aarhus, Aarhus University Hospital, Hedeager, Aarhus N, Denmark, 2Department of \\ Obstetrics and Gynecology, and ${ }^{3}$ Medical Research Laboratories, Department of Diabetes and Endocrinology, Aarhus \\ University Hospital, Palle Juul Jensens Boulevard, Aarhus N, Denmark
}

Correspondence

should be addressed

to U Kampmann

Email

ulla@opstrup.dk

\section{Summary}

During pregnancy, maternal tissues become increasingly insensitive to insulin in order to liberate nutritional supply to the growing fetus, but occasionally insulin resistance in pregnancy becomes severe and the treatment challenging. We report a rare and clinically difficult case of extreme insulin resistance with daily insulin requirements of $1420 \mathrm{IU} /$ day during pregnancy in an obese 36-year-old woman with type 2 diabetes (T2D) and polycystic ovary syndrome (PCOS). The woman was referred to the outpatient clinic at gestational week $12+2$ with a hemoglobin A1c (HbA1c) at $59 \mathrm{mmol} / \mathrm{mol}$. Insulin treatment was initiated immediately using Novomix 30, and the doses were progressively increased, peaking at 1420 units/day at week $34+4$. At week $35+0$, there was an abrupt fall in insulin requirements, but with no signs of placental insufficiency. At week $36+1$ a, healthy baby with no hypoglycemia was delivered by cesarean section. Blood samples were taken late in pregnancy to search for causes of extreme insulin resistance and showed high levels of C-peptide, proinsulin, insulin-like growth factor (IGF-1), mannan-binding-lectin (MBL) and leptin. CRP was mildly elevated, but otherwise, levels of inflammatory markers were normal. Insulin antibodies were undetectable, and no mutations in the insulin receptor (INSR) gene were found. The explanation for the severe insulin resistance, in this case, can be ascribed to PCOS, obesity, profound weight gain, hyperleptinemia and inactivity. This is the first case of extreme insulin resistance during pregnancy, with insulin requirements close to $1500 \mathrm{IU} /$ day with a successful outcome, illustrating the importance of a close interdisciplinary collaboration between patient, obstetricians and endocrinologists.

\section{Learning points:}

- This is the first case of extreme insulin resistance during pregnancy, with insulin requirements of up to 1420 IU/ day with a successful outcome without significant fetal macrosomia and hypoglycemia.

- Obesity, PCOS, T2D and high levels of leptin and IGF-1 are predictors of severe insulin resistance in pregnancy.

- A close collaboration between patient, obstetricians and endocrinologists is crucial for tailoring the best possible treatment for pregnant women with diabetes, beneficial for both the mother and her child.

\section{Background}

During pregnancy, maternal tissues become increasingly insensitive to insulin in order to redistribute an adequate amount of nutritional supply to the growing fetus. The degree of maternal insulin resistance during pregnancy is associated with the degree of glucose flux from the mother to the fetus (1). Maternal hyperglycemia leads to fetal hyperglycemia and hyperinsulinemia, which causes fetal macrosomia - one of the most common and serious pregnancy complications of maternal diabetes and obesity (2). A 50-70\% decrease in insulin sensitivity is seen with advancing gestation in women with normal glucose tolerance and with diabetes (1). Occasionally, insulin resistance in pregnancy becomes severe, and the treatment is a challenge to both doctor and patient. 
Here we describe a rare and clinically challenging case, concerning a pregnant woman with T2D and extreme insulin resistance with insulin requirements of up to 1420 IU insulin per day.

\section{Case presentation}

A36-year-old woman, diagnosed with PCOS and T2D 7 years previously, was referred to the outpatient clinic for pregnant women with diabetes at Aarhus University Hospital (AUH) in pregnancy week $12+2$. Prior to pregnancy, she had had irregular periods, but a significant weight loss of $30 \mathrm{~kg}$ let to regular periods and a spontaneous pregnancy. The patient's pre-pregnancy BMI was $40 \mathrm{~kg} / \mathrm{m}^{2}$, and her blood pressure was $136 / 71 \mathrm{mmHg}$ at the first visit and remained stable throughout pregnancy. She had previously been treated with metformin, liraglutide, and an ACE inhibitor, but her general practitioner had discontinued all medication after the weight loss as $\mathrm{HbA} 1 \mathrm{c}$ was $41 \mathrm{mmol} / \mathrm{mol}$ and blood pressure was normal. In addition, the woman did not have any medical history or any clinical or biochemical features of lipodystrophy, severe acanthosis nigricans, hirsutism, obstructive sleep apnea, Cushing's syndrome, acromegaly or hyperthyroidism that could contribute to severe insulin resistance.

When the patient was referred to the outpatient clinic, $\mathrm{HbA} 1 \mathrm{c}$ was $59 \mathrm{mmol} / \mathrm{mol}$. Insulin treatment was initiated immediately using Novomix 30 (insulin aspart with both a rapid-acting and an intermediate-acting effect, in the ratio 30/70) 20 units/day. The doses were progressively increased (Fig. 1A and Table 1) and when the patient reached 180 units/day, the insulin regime was changed to Insulatard (intermediate-acting human insulin isophane) twice a day and Novorapid (insulin aspart with a rapidacting effect) three to five times a day. When the patient reached 1420 units/day at week $34+4$, additional blood samples were taken to search for the cause of this extreme insulin resistance. At week $35+0$, there was an abrupt fall in insulin requirements to 720 units/day, but with no signs of placental insufficiency as estimated by fetal heart rate tracings and fetal ultrasound scans, including flow measurements. The patient was admitted for observation, and insulin requirements and blood glucose continued to fall. At week $35+4$, the patient had no insulin requirements and kept a stable blood glucose at around $6 \mathrm{mmol} / \mathrm{L}$ for the next 4 days until delivery by cesarean section at week $36+1$, after an unsuccessful attempt of induction of labor due to the dramatic change in insulin requirements.

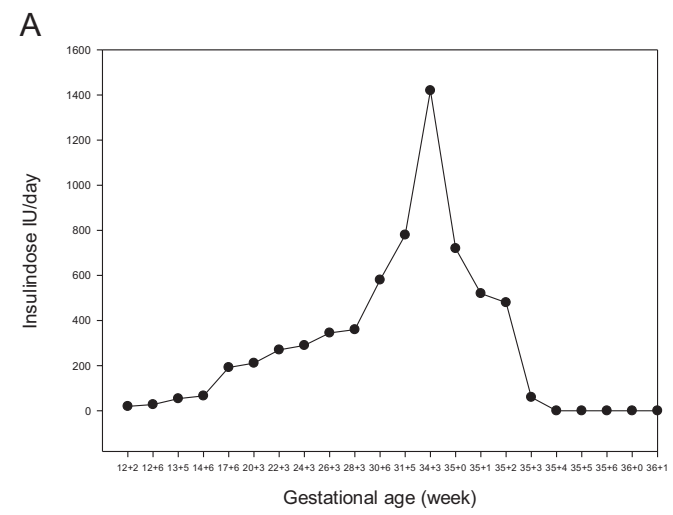

B

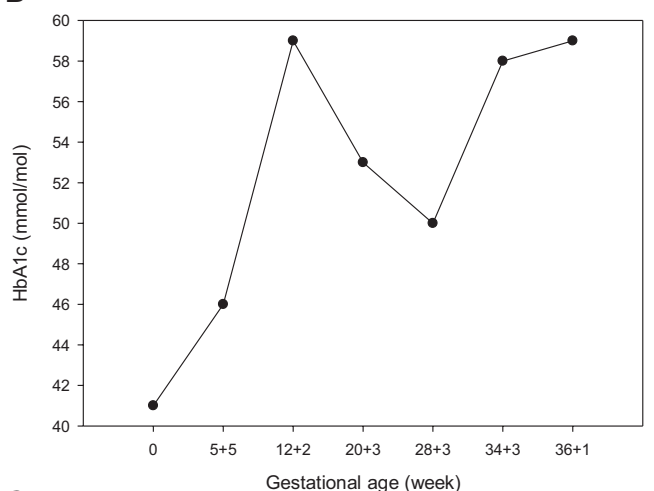

C
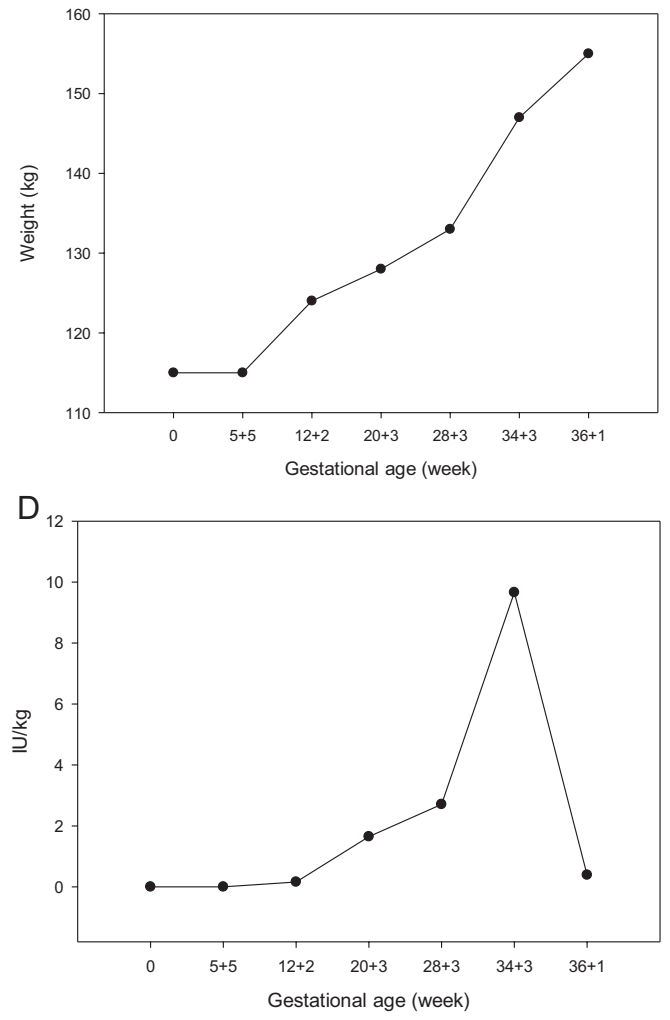

Figure 1

Changes in insulin doses (A) and $\mathrm{HbA1C}(\mathrm{B})$ and weight (C) and (D) insulin units/kg during pregnancy. 
Table 1 Insulin doses during pregnancy.

\begin{tabular}{l}
$\begin{array}{l}\text { Gestational age } \\
\text { (week) }\end{array}$ \\
\hline $12+2$ \\
$12+6$ \\
$13+5$ \\
$14+6$ \\
$17+6$ \\
$20+3$ \\
$22+3$ \\
$24+3$ \\
$26+3$ \\
$28+3$ \\
$30+6$ \\
$31+5$ \\
$34+3$ \\
$35+0$ \\
$35+1$ \\
$35+2$ \\
$35+3$ \\
$35+4$ \\
$35+5$ \\
$35+6$ \\
$36+0$ \\
$36+1$ (cesarean \\
section) \\
\hline
\end{tabular}

Weight

Hba1C

(kg)
$(\mathrm{mmol} / \mathrm{mol})$

- $\frac{(\mathrm{m} 9}{\mathrm{N}}$

\section{Investigation}

Results of blood samples are shown in Table 2. The patient was severely insulin resistant with a non-fasting C-peptide concentration of $3294 \mathrm{pmol} / \mathrm{L}$ (reference range 370-1470 pmol/L) and an extremely high level of proinsulin of $302 \mathrm{pmol} / \mathrm{L}$ (reference range 2.1-13 pmol/L). Leptin and MBL levels were also high as was the level of IGF-1 (401 $\mu \mathrm{g} / \mathrm{L}$; reference range 69-227 $\mu \mathrm{g} / \mathrm{L}$ ), but it corresponded to third-trimester levels of IGF-1 in pregnant women without diabetes (3). Inflammatory markers adiponectin, cytokines (interleukin-6 (IL-6) and tumor necrosis factor $\alpha$ (TNF- $\alpha$ ) and high sensitive CPR (hsCRP) were comparable to other women with gestational diabetes (GDM) in late pregnancy (4), whereas fibroblast growth factor 21 (FGF-21) levels were relatively low. CRP was mildly elevated, which is a typical feature of PCOS, and free fatty acids (FFA) were low due to the high doses of exogenous insulin administration. CD 163, cortisol and standard biochemical profile, including lipid profile, was unremarkable and antibodies against insulin were undetectable. The patient gave written informed consent to have coding exons and introns of the INSR gene examined, but no mutations were detected.

The development in HbA1c during pregnancy is shown in Fig. 1B, and as the target HbA1c for pregnant women with diabetes in Denmark is $6.5 \%$ (48 $\mathrm{mmol} / \mathrm{mol})$ before gestational week 20 and 5.6\% (37 mmol/mol) after week 20 , the patient was never optimally controlled during pregnancy, despite the frequent increase in insulin doses. Although the patient was advised not to gain more than 0-5 kg during pregnancy, she gained $40 \mathrm{~kg}$ from $115 \mathrm{~kg}$ prior to pregnancy to $155 \mathrm{~kg}$, and the weight gain coincided with the increase in insulin requirements as shown in Fig. 1.

\section{Treatment}

The specific increase in insulin doses are outlined in Table 1. Diabetes regulation was managed by selfmonitoring of glucose seven times a day, and frequent insulin adjustments were performed in close collaboration with endocrinologists, aiming at capillary plasma glucose levels of $4-6 \mathrm{mmol} / \mathrm{L}$ preprandial and 4-8 mmol/L $1 \frac{1}{2} \mathrm{~h}$ after meals. Dietary advice, caloric restriction and exercise recommendations were given along with insulin treatment.

\section{Outcome and follow-up}

At week $36+1$ a healthy baby was delivered by cesarean section. Apgar scores at 1, 5 and 10 min were normal, and 
Table 2 Hormones and inflammatory markers.

\begin{tabular}{l}
\hline Gestational age (week + days) \\
\hline P-Insulin $(18-173 \mathrm{pmol} / \mathrm{L})$ \\
C-peptide $(370-1470 \mathrm{pmol} / \mathrm{L})$ \\
P-proinsulin $(2.1-13 \mathrm{pmol} / \mathrm{L})$ \\
Insulin antibody $(<10$ negative $)$ \\
Prolactin $\left(90-580 \times 10^{-3} \mathrm{IU} / \mathrm{L}\right)$ \\
IGF-1 $(69-227 \mu \mathrm{g} / \mathrm{L})$ \\
P-cortisol $(171-536 \mathrm{nmol} / \mathrm{L})$ \\
CRP $(<8.0 \mathrm{mg} / \mathrm{L})$ \\
CD163 $(0.69-3.86 \mathrm{mg} / \mathrm{L})$ \\
Adiponectin $(\mathrm{mg} / \mathrm{L})$ \\
FFA $(\mathrm{mmol} / \mathrm{L})$ \\
hsCRP $(\mathrm{mg} / \mathrm{L})$ \\
MBL $(\mathrm{ng} / \mathrm{mL})$ \\
IL-6 $(\mathrm{pg} / \mathrm{mL})$ \\
TNF- $\alpha(\mathrm{pg} / \mathrm{mL})$ \\
Leptin $(\mu \mathrm{g} / \mathrm{L})$ \\
FGF-21 $(\mathrm{ng} / \mathrm{L})$ \\
\hline
\end{tabular}

\begin{tabular}{c}
\hline $\mathbf{3 5 + 3}$ \\
\hline 923 \\
3294 \\
102 \\
4 \\
5280 \\
401 \\
377 \\
14 \\
2.02 \\
7.70 \\
0.46 \\
10.2 \\
2418 \\
1.48 \\
6.91 \\
117.6 \\
181.2 \\
\hline
\end{tabular}

$\frac{\mathbf{3 5 + 4}}{1295}$
177

\begin{tabular}{r}
\hline $\mathbf{3 5 + 5}$ \\
\hline 228 \\
1623
\end{tabular}

\begin{tabular}{c}
\hline $\mathbf{2}$ days pp \\
\hline 76 \\
1275
\end{tabular}

\begin{tabular}{c}
\hline $\mathbf{7}$ months pp \\
\hline 258 \\
1836 \\
76
\end{tabular}

IGF-1, insulin-like growth factor; FFA, free fatty acids; hsCRP, high sensitive CRP; MBL, mannan-binding lectin; IL-6, interleukin-6; TNF- $\alpha$, tumor necrosis factor $\alpha$; FGF-21, fibroblast growth factor 21.

the baby had no abnormalities. The birthweight was 3850 g, large for gestational age with a z-score of 3.05, and the blood glucose was $2.8 \mathrm{mmol} / \mathrm{L} 1$ hour $1 \mathrm{~h}$ after delivery, and $4.3 \mathrm{mmol} / \mathrm{L} 4 \mathrm{~h}$ after delivery, compatible with no neonatal hypoglycemia. Placental weight was $920 \mathrm{~g}$. Mother and baby were discharged from the hospital 5 days after delivery, and the patient was advised to continue selfmonitoring of glucose regularly and consult her general practitioner for diabetes check-up.

Shortly after delivery, blood glucose, plasma insulin, C-peptide and IGF-1 normalized and as the patient was breastfeeding, she did not receive any antidiabetic medication. Seven months post-partum, insulin, C-peptide and proinsulin had increased above reference range and $\mathrm{HbA1c}$ was $116 \mathrm{mmol} / \mathrm{mol}$, indicating that insulin resistance had returned and that treatment was warranted.

\section{Discussion}

We report a rare and clinically difficult case of extreme insulin resistance with daily insulin requirements of $\sim 1500$ IU/day during pregnancy in an obese woman with T2D and PCOS. To our knowledge, such a case has never been described in the literature before.

First of all, it is relevant to raise the question: did the patient really take $1500 \mathrm{IU} /$ day? As the patient's therapists, we do not have any reason to believe the opposite. We had close contact with the patient at least once a week, where insulin doses were verified by the patient and adjusted according to blood glucose profiles. The patient seemed compliant and collection of insulin pens at the pharmacy was confirmed in the prescription database. The high levels of insulin measured in the blood samples also confirmed that the patient was compliant.

Secondly, why did the patient get so insulin resistant? The determinants and causal mechanisms of insulin resistance in pregnancy are complex and still not completely revealed (5), but it is well-known that obesity and PCOS, factors that were predominant, in this case, are strongly associated with insulin resistance. The massive weight gain, in this case, is especially important, given that it induces insulin resistance, which in turn leads to higher insulin requirements and consequent weight gain, creating a vicious cycle. Additionally, the patient was previously diagnosed with $\mathrm{T} 2 \mathrm{D}$, where insulin resistance is an important part of the pathophysiology.

The changes in insulin sensitivity during pregnancy are also believed to be caused partly by hormones, cytokines and adipokines from the placenta, but no single hormone has been found to explain the insulin resistance in pregnancy.

In the present case, we measured different hormones and cytokines (Table 2) and found that IGF-1, leptin and MBL were abnormally high. Hyperleptinemia is a result of an increased synthesis and secretion from abundant adipose tissue (6), but leptin is also secreted in the placenta and leptin levels increase substantially during pregnancy. McIntyre et al. conclude that maternal insulin sensitivity in pregnancy is positively associated with leptin and the growth hormone axis (7), and as these parameters were 
very high in the present case, they might account for the extreme insulin resistance.

MBL plays a role in the immune system as it activates the complement system and has been linked to diabetic nephropathy and the risk of cardiovascular disease in diabetes $(8,9)$. MBL levels increase up to $140 \%$ during pregnancy with a sharp decrease after delivery (10) and is speculated to contribute to a normal placentation and pregnancy. However, previous studies have found, that serum MBL levels are positively related to insulin sensitivity in women with PCOS (11) and can therefore not explain the severe insulin resistance in our case.

Only very few cases exist on extreme insulin resistance in pregnancy. One other case describes a woman with insulin requirements of daily doses up to $480 \mathrm{IU} /$ day. The reason for the insulin resistance was a heterozygous $\Delta$ Leu $^{999}$ mutation found in the INSR gene, and treatment with metformin reduced the insulin requirements substantially to $150 \mathrm{IU} /$ day in the following pregnancy (12). Although there were no mutations found in the INSR gene in our case, metformin could have been added in order to spare insulin by sensitizing insulin action through suppressing hepatic glucose output or increasing glucose uptake in peripheral tissues. However, although metformin is considered safe in pregnancy (13), it is not recommended for pregnant women in Denmark and is therefore only used in very rare cases.

It would also have been worth considering using high concentrate insulin (insulin degludec $200 \mathrm{IE} / \mathrm{mL}$ or insulin glargine $300 \mathrm{IE} / \mathrm{mL}$ ), but these insulin products are mostly used for patients with type 1 diabetes and a change to another type of insulin during pregnancy could potentially lead to unwanted excursions in blood glucose levels. Moreover, results from ongoing studies using high concentrate insulin in pregnant women with diabetes are pending. A retrospective study has however shown improved glycemic control in pregnant women with severe insulin resistance when using $500 \mathrm{IU} / \mathrm{mL}$ concentrated insulin (14), but this type of insulin is not available in Denmark. The great challenge in the current case was the continuous increase in insulin requirements and the balance between hypo- and hyperglycemia. One could speculate if very high doses of insulin have any clinical effect. A previous dose-response study in severely insulin-resistant patients with T2D, however, showed that a dose-response relationship to insulin is maintained at very high doses and it thus seems reasonable to increase insulin doses in these patients in order to accomplish optimal glycemic control (15). The patient in the present case did not accomplish optimal control, based on the HbA1c measurements, despite the extremely large doses of insulin, and at delivery, the baby was large for gestational age, but did not suffer from hypoglycemia.

Also, the patient did not experience episodes of hypoglycemia until GA $35+0$, where insulin requirements suddenly declined rapidly and the patient had to reduce insulin doses substantially, ending up with no insulin requirements the last 5 days prior to delivery. The reason for this rapid decline remains unclear, as there were no signs of placental insufficiency or lipohypertrophia at the injection sites. Nevertheless, the rapid and dramatic changes in insulin requirements led to the induction of labor to foreclose that a potential placental insufficiency had consequences for the fetal well-being.

\section{Conclusion}

Insulin resistance during pregnancy is accentuated in situations with diabetes, PCOS, obesity and inactivity and can become severe. We experienced a therapeutic challenge in a pregnant women with a history of PCOS, obesity and T2D with extreme needs for exogenous insulin, but through a close collaboration between patient, obstetricians and endocrinologists a successful outcome was obtained. Metformin might potentially have reduced insulin doses, but is considered experimental in Denmark and was therefore not attempted.

\section{Declaration of interest}

The authors declare that there is no conflict of interest that could be perceived as prejudicing the impartiality of the research reported.

\section{Funding}

This research did not receive any specific grant from any funding agency in the public, commercial or not-for-profit sector, but the salary for UK is provided by the Danish Diabetes Academy and PO is supported by The Novo Nordisk Foundation.

\section{Patient consent}

Written informed consent was obtained from the patient for publication of this case report.

\section{Author contribution statement}

U K, P O and J F collected data. U K wrote the manuscript. U K, P O, N M and J F were in charge of the patient treatment and P O, N M and J F contributed to the manuscript. 


\section{References}

1 Catalano PM. Trying to understand gestational diabetes. Diabetic Medicine 201431 273-281. (https://doi.org/10.1111/dme.12381)

2 HAPO Study Cooperative Research Group, Metzger BE, Lowe LP, Dyer AR, Trimble ER, Chaovarindr U, Coustan DR, Hadden DR, McCance DR, Hod M, et al. Hyperglycemia and adverse pregnancy outcomes. New England Journal of Medicine 2008358 1991-2002. (https://doi.org/10.1056/NEJMoa0707943)

3 Chellakooty M, Vangsgaard K, Larsen T, Scheike T, Falck-Larsen J, Legarth J, Andersso AM, Main KM, Skakkebæk NE \& Juul A. A longitudinal study of intrauterine growth and the placental growth hormone (GH)-insulin-like growth factor I axis in maternal circulation: association between placental GH and fetal growth. Journal of Clinical Endocrinology and Metabolism 200489 384-391. (https://doi.org/10.1210/jc.2003-030282)

4 Skajaa GO, Fuglsang J, Knorr S, Møller N, Ovesen PO \& Kampmann U. Changes in insulin sensitivity and insulin secretion during pregnancy and postpartum in women with gestational diabetes mellitus. BMJ Open Diabetes Research and Care 20208 e001728. (https://doi. org/10.1136/bmjdrc-2020-001728)

5 Kampmann U, Knorr S, Fuglsang J \& Ovesen P. Determinants of maternal insulin resistance during pregnancy: an updated overview. Journal of Diabetes Research 20192019 5320156. (https://doi. org/10.1155/2019/5320156)

6 Askari H, Tykodi G, Liu J \& Dagogo-Jack S. Fasting plasma leptin level is a surrogate measure of insulin sensitivity. Journal of Clinical Endocrinology and Metabolism 201095 3836-3843. (https://doi. org/10.1210/jc.2010-0296)

7 McIntyre HD, Chang AM, Callaway LK, Cowley DM, Dyer AR, Radaelli T, Farrell KA, Huston-Presley L, Amini SB, Kirwan JP, et al. Hormonal and metabolic factors associated with variations in insulin sensitivity in human pregnancy. Diabetes Care 201033 356-360. (https://doi.org/10.2337/dc09-1196)

8 Gedebjerg A, Bjerre M, Kjaergaard AD, Steffensen R, Nielsen JS Rungby J, Friborg SG, Brandslund I, Thiel S, Beck-Nielsen H, et al.
Mannose-binding lectin and risk of cardiovascular events and mortality in Type 2 diabetes: a Danish cohort study. Diabetes Care 2020 43 2190-2198. (https://doi.org/10.2337/dc20-0345)

9 Flyvbjerg A. The role of the complement system in diabetic nephropathy. Nature Reviews: Nephrology 201713 311-318. (https://doi. org/10.1038/nrneph.2017.31)

10 van de Geijn FE, Roos A, de Man YA, Laman JD, de Groot CJM, Daha MR, Hazes JM \& Dolhain RJ. Mannose-binding lectin levels during pregnancy: a longitudinal study. Human Reproduction 200722 362-371. (https://doi.org/10.1093/humrep/del392)

11 Kowalska I, Fernandez-Real JM, Straczkowski M, Kozlowska A, Adamska A, Ortega F, Nikolajuk A, Karczewska-Kupczewska M, Wolczynski S \& Gorska M. Insulin resistance Is associated with decreased circulating mannan-binding lectin concentrations in women with polycystic ovary syndrome. Diabetes Care 200831 e20-e20. (https://doi.org/10.2337/dc07-1872)

12 Enkhtuvshin B, Nagashima S, Saito N, Wakabayashi T, Ando A, Takahashi M, Sakai K, Yamamuro D, Nagasaka S, Tamemoto H, et al. Successful pregnancy outcomes in a patient with type A insulin resistance syndrome. Diabetic Medicine 201532 e16-e19. (https://doi. org/10.1111/dme.12659)

13 Given JE, Loane M, Garne E, Addor MC, Bakker M, Bertaut-Nativel B, Gatt M, Klungsoyr K, Lelong N, Morgan M, et al. Metformin exposure in first trimester of pregnancy and risk of all or specific congenital anomalies: exploratory case-control study. BMJ 2018361 k2477. (https://doi.org/10.1136/bmj.k2477)

14 Mendez-Figueroa H, Maggio L, Dahlke JD, Daley J, Lopes VV, Coustan DR \& Rouse DJ. Treatment of severe insulin resistance in pregnancy with 500 units per milliliter of concentrated insulin. Obstetrics and Gynecology 2013122 99-104. (https://doi.org/10.1097/ AOG.0b013e3182978a11)

15 Kampmann U, Hoeyem P, Mengel A, Schmitz O, Rungby J, Orskov L \& Møller N. Insulin dose-response studies in severely insulin-resistant type 2 diabetes - evidence for effectiveness of very high insulin doses. Diabetes, Obesity and Metabolism 201113 511-516. (https://doi. $\operatorname{org} / 10.1111 / \mathrm{j} .1463-1326.2011 .01373 . x)$

Received in final form 18 May 2021

Accepted 27 May 2021 